\title{
Two-dimensional Correlation Gel Permeation Chromatography (2D GPC) Study of Aggregate-Aggregate Interactions during Polymerization of 3-(Triethoxysilyl)propyl-terminated Polystyrene
}

\author{
Keita SuZuKI, ${ }^{1}$ Jun-ichi OKu, ${ }^{1}$ Kenichi IZAwa, ${ }^{2}$ Hiro-Fumi OKABAYAshI,${ }^{1, \dagger}$ \\ Isao NODA, ${ }^{3}$ and Charmian J. O' $\mathrm{CONNOR}^{4}$ \\ ${ }^{1}$ Department of Applied Chemistry, Nagoya Institute of Technology, \\ Gokiso-cho, Showa-ku, Nagoya 466-8555, Japan \\ ${ }^{2}$ Fuji Silysia Chemical Ltd., Chromato Dept., 1846, Kozoji2, Kasugai 487-0013, Japan \\ ${ }^{3}$ The Procter and Gamble Company, 8611 Beckett Road, West Chester, OH 45069, U.S.A. \\ ${ }^{4}$ Department of Chemistry, The University of Auckland, Private Bag 92019, Auckland, New Zealand
}

(Received June 28, 2004; Accepted September 9, 2004; Published December 15, 2004)

\begin{abstract}
The three-step polymerization process of a well-defined polymeric silane coupling agent, 3-(triethoxysilyl)propyl-terminated polystyrene, catalyzed by $1 \mathrm{~mol} / \mathrm{kg} \mathrm{KOH}-\mathrm{H}_{2} \mathrm{O}$, was traced as a function of reaction time using a gel-permeation chromatography (GPC) technique. A set of GPC traces collected during the polymerization was then converted to two-dimensional (2D) correlation maps, by using generalized 2D correlation analysis. The 2D correlation GPC maps reflected the details of the aggregational behavior (in particular, the aggregate-aggregate correlations) in each step of the polymerization, thus demonstrating the promising potential of this technique.

[DOI 10.1295/polymj.36.959]

KEY WORDS 3-(Triethoxysilyl)propyl-terminated Polystyrene / Polymerization / 2D GPC / KOH Catalyst / Aggregate-Aggregate Correlations / Oligomer /
\end{abstract}

The two-dimensional (2D) correlation technique ${ }^{1-3}$ has been applied successfully to analysis of dynamic spectral intensity variations of various molecular spectra, such as IR, Raman, and Near IR. ${ }^{4-9}$ It is therefore expected that this technique could also become a potential tool for studying the details of reaction dynamics and mechanisms in a polymerization process.

Two-dimensional correlation gel permeation chromatography (2D correlation GPC) has been introduced, for the first time, to examine intricate details of the polymerization of some simple silane coupling agents. ${ }^{10-14}$ It has been found that 2D correlation GPC spectra reflect directly the reaction mechanism of a polymerization process. ${ }^{12-14}$ For the $\mathrm{HCl}$-catalyzed polymerization of perfluorooctyl-triethoxysilane, 2D correlation GPC results have demonstrated that each elution band consists of two (reactive and less-reactive) components and that rapid growth of the polymeric aggregates may be caused by the appearance of the reactive components. ${ }^{13}$

In 2D correlation GPC, ${ }^{10-14}$ a series of GPC traces is collected as a function of the sampling time, e.g., reaction time during the course of polymerization. The time-resolved GPC traces are then converted to two-dimensional correlation spectra by using a simple mathematical cross-correlation analysis. The 2D correlation GPC spectra thus calculated provide signifi- cant information not readily observable by conventional GPC methods.

In this present study, we report the 2D correlation analysis of time-resolved GPC profiles of the polymeric silane coupling agent (SCA), 3-(triethoxysilyl) propyl-terminated polystyrene (TESiP-PS) (molecular weight: 2500$)-\mathrm{KOH} \cdot \mathrm{H}_{2} \mathrm{O}$ system, in order to elucidate the aggregational behavior of the polymerizing precursors. The molecular weight $\left(M_{\mathrm{n}} \geq 2500\right)$ of the polymeric aggregates can be easily estimated from a polystyrene-standard calibration curve, and compared with the case of an SCA with low molecular weight (usually, $M_{\mathrm{n}}<500$ ). Thus, the aggregate-aggregate correlations in the aggregational process can be studied in detail.

So-called cross-correlation chromatography (CCC) has been used in the past for trace analysis. ${ }^{15-18}$ However, the CCC method, which is based on classical statistics, cannot extract the asynchronous nature of dynamic processes characteristic of complex multiple stage polymerization reactions. The concept of a generalized $2 \mathrm{D}$ correlation, as introduced by Noda,${ }^{2}$ made it possible to analyze systematically such asynchronous characteristics.

Recently, a polymeric SCA, an alkoxysilyl-terminated macromonomer, has been examined, in order to obtain fundamental information on increased inter-

${ }^{\dagger}$ To whom correspondence should be addressed (fwiw4348@mb.infoweb.ne.jp). 
facial strength of a surface when such a material is used for reinforcement. ${ }^{19-23}$ Further study of the aggregational behavior of such a polymeric SCA is highly desirable, especially in connection with the mechanical properties of SCA modified materials. Nishio et al. ${ }^{24}$ investigated the polymerization process of a simple SCA, 3-aminopropyltriethoxysilane, on the surface of glass, and found that the reactivity of silane molecules and the characteristics of reinforcement materials may be associated with the molecular structure of the modified SCA.

The self-assembling behavior of the styryl- and butadienyl-lithium head groups attached to a polystyrene chain was studied by Fetters et al. ${ }^{25}$ The results indicated that the intermediate-sized aggregates coexisted with larger scale structures of aggregate size of approximately $10^{3} \AA$. Stellbrink et al. ${ }^{26}$ examined the aggregational behavior of styryl lithium head groups in benzene by using small angle neutron scattering. The results showed that dimers and tetramers were formed in a first step and that larger scale selfassembled aggregates may be formed. However, very little is known currently about aggregate-aggregate interactions during polymerization.

\section{THEORETICAL BACKGROUND}

A detailed theoretical background to 2D correlation spectra has been provided previously. ${ }^{12}$ A summary is given below.

The time-resolved GPC trace intensity $I(E, t)$ can be expressed as a function of the chromatographic elution time $E$ and the sampling time $t$ of the polymerization reaction for each aliquot collected during the period between $T_{\min }$ and $T_{\max } \cdot{ }^{10-12,14}$ The reference GPC trace $\bar{I}(E)$ is set to be the time-average of trace profiles over the observation period, defined by

$$
\bar{I}(E)=\frac{1}{T_{\max }-T_{\min }} \int_{T_{\min }}^{T_{\max }} I(E, t) \mathrm{d} t .
$$

If the reference trace is set equal to zero, then the dynamic trace is identical to the observed variation in the GPC profile, and eq 1 may be used for the 2D GPC analysis.

The generalized 2D correlation function ${ }^{2,3}$ used to analyze time-resolved GPC is formally defined as

$$
\begin{aligned}
& \Phi\left(E_{1}, E_{2}\right)+\mathrm{i} \Psi\left(E_{1}, E_{2}\right) \\
& \quad=\frac{1}{\pi\left(T_{\max }-T_{\min }\right)} \int_{0}^{\infty} \tilde{Y}_{1}(\omega) \cdot \tilde{Y}_{2}^{*}(\omega) \mathrm{d} \omega .
\end{aligned}
$$

The real and imaginary components of the 2D correlation function, $\Phi\left(E_{1}, E_{2}\right)$ and $\Psi\left(E_{1}, E_{2}\right)$, are known as the synchronous and asynchronous $2 \mathrm{D}$ correlation intensities, respectively. The synchronous intensity represents the overall similarity or coincidental trends between two separate concentration indicator variations (e.g., refractive index (RI) intensities) of the GPC trace measured at different elution counts, as the sampling (i.e., reaction) time, $t$, is increased from $T_{\min }$ to $T_{\max }$. The asynchronous intensity may be regarded as a measure of dissimilarity (or out-of-phase character) of the GPC intensity variations.

The term $\tilde{Y}_{1}(\omega)$ is the forward Fourier transform of the dynamic intensity variations $\tilde{y}\left(E_{1}, t\right)$ observed at a specific elution count $E_{1}$ with respect to the sampling time $t$, is expressed by

$$
\tilde{Y}_{1}(\omega)=\int_{-\infty}^{\infty} \tilde{y}\left(E_{1}, t\right) \mathrm{e}^{-\mathrm{i} \omega t} \mathrm{~d} t .
$$

The Fourier integration of the dynamic spectrum is bound by the finite interval between $T_{\min }$ and $T_{\max }$. Once the appropriate Fourier transformation of the dynamic trace $\tilde{y}(E, t)$ is carried out as a function of the sampling time, $t$, eq 2 provides directly the synchronous and asynchronous correlation spectra, $\Phi\left(E_{1}, E_{2}\right)$ and $\Psi\left(E_{1}, E_{2}\right)$.

\section{Synchronous 2D GPC Spectrum}

The intensity of a synchronous 2D GPC correlation spectrum $\Phi\left(E_{1}, E_{2}\right)$ represents the simultaneous changes of the trace-intensity variations measured at elution times $E_{1}$ and $E_{2}$ during the reaction process. A synchronous spectrum is symmetric with respect to the diagonal line corresponding to the coordinates $E_{1}=E_{2}$. Correlation peaks appear at both diagonal and off-diagonal positions. The intensity of the diagonal peaks (autopeaks) corresponds to the autocorrelation function of the variations in RI intensity observed during the reaction. The magnitude of the intensity of such a peak represents the overall extent of variation in the trace intensity observed along the reaction time at a specific elution count $E$, and its incidence represents the overall susceptibility of the corresponding GPC peak to change in intensity as the reaction proceeds.

The cross peaks represent the simultaneous change of spectral intensities observed at $E_{1}$ and $E_{2}$. The sign of autopeaks is always positive, while that of the cross peaks may be either positive or negative. If the traceintensities at the two elution times are both increasing or decreasing as the reaction proceeds, then the synchronous cross peaks is positive. Conversely, a negative sign for the cross peaks indicates that the two trace intensities are moving in opposite directions.

Thus, the presence of a cross peak in a synchronous 2D spectrum represents simultaneous, or synchronized changes of the spectral intensities observed at $E_{1}$ and $E_{2}$, and implies the possible existence of a coupled or related origin for the variation in GPC trace intensity. A synchronous correlation square (CSq) may be con- 
structed by connecting the two autopeaks and the two cross peaks, thereby implicating the existence of a coherent variation in GPC trace intensities at these spectral variables.

\section{Asynchronous 2D GPC Spectrum}

The intensity of an asynchronous spectrum represents sequential, or successive changes in GPC trace intensities measured at $E_{1}$ and $E_{2}$. An asynchronous spectrum, which is antisymmetric with respect to the diagonal line, has no autopeaks and consists exclusively of off-diagonal cross peaks. An asynchronous cross peak develops only if the intensities of two GPC trace features change out of phase with respect to each other as the reaction proceeds.

The sign of asynchronous cross peaks may be either negative or positive. When the intensity change at $E_{1}$ occurs predominantly before $E_{2}$ in the sequential sampling time $t$, the asynchronous cross peak is positive. Conversely, if the change occurs after $E_{2}$, its sign is negative. However, when the intensity, at the same coordinate, of the corresponding synchronous peak is negative, i.e., $\Phi\left(E_{1}, E_{2}\right)<0$, this rule is reversed. ${ }^{2}$

The existence of a positive cross peak in the asynchronous spectrum, and of a negative cross peak at this same position in the synchronous map, indicate that the $E_{1}$ component changes first and after same time delay, the $E_{2}$ component changes. Thus, the asynchronous map provides information on the order of events.

\section{EXPERIMENTAL}

\section{Materials}

sec-Butyllithium ( $s$-BuLi; Aldrich, 1.3 M in cyclohexane) was used after filtration and solvent replacement with benzene. These treatments were carried out under high vacuum $\left(10^{-5} \mathrm{~mm} \mathrm{Hg}\right)$ using a vacuum line. Styrene was purified as previously described. ${ }^{27}$ 3-Chloropropyltriethoxysilane (CPTESi; Shin-Etsu Silicon Chemicals) was dried on a vacuum line over $\mathrm{CaH}_{2}$ for $24 \mathrm{~h}$, and then distilled. Catalyst $(\mathrm{KOH})$ and solvent (tetrahydrofuran (THF)) used for the condensation were reagent grade and were used as received.

\section{Preparation of 3-(Triethoxysilyl)propyl-terminated Polystyrene}

Living polystyrene (PS) with molecular weight $\left(M_{\mathrm{n}}\right)$ equal to 2300 was prepared by anionic polymerization of styrene, which was purified immediately prior to polymerization with the initiator $s$-BuLi. 3-(Triethoxysilyl)propyl-terminated polystyrene (TESiP-PS) with $M_{\mathrm{n}}$ equal to 2500 was prepared by the coupling reaction of living PS and CPTESi. ${ }^{27}$ The TESiP-PS,

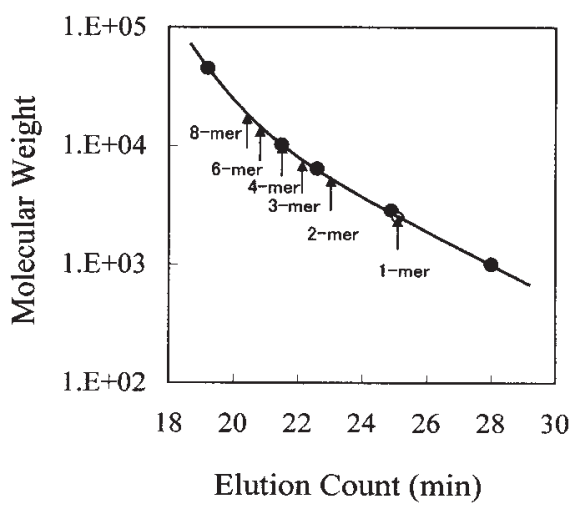

Figure 1. Calibration curve of polystyrene standards.

thus obtained by reprecipitation in methanol, was dried in vacuum at $c a .298 \mathrm{~K}$.

\section{Condensation and Time-resolved GPC Measurements}

TESiP-PS, catalyst $\left(\mathrm{KOH}, 1 \mathrm{~mol} / \mathrm{kg} \mathrm{H}_{2} \mathrm{O}\right)$ and THF were placed into each ampoule, sealed under high vacuum $\left(10^{-3} \mathrm{~mm} \mathrm{Hg}\right)$ and the contents were homogenized by shaking. The condensation of TESiP-PS was carried out in a temperature-controlled bath. Each reaction mixture was kept at $333 \mathrm{~K}$ for a prescribed time. The resulting polymer was recovered by pouring the reaction mixture into a large excess of methanol, in order to quench the condensation. The polymer precipitated from each reaction mixture was filtered through a glass filter and dried at $c a .298 \mathrm{~K}$.

GPC curves were recorded on a Tosoh HLC-802UR (G2000H and $\mathrm{G} 3000 \mathrm{H}$ columns) at a column oven temperature of $313 \mathrm{~K}$. THF was used as the eluent. The GPC data were calibrated with PS standards (Figure 1). The nominal flow rate of the eluent was $1 \mathrm{~mL} / \mathrm{min}$; actual flow rates were inspected during the recording of a GPC curve and their constancy was confirmed. Thus, we have assumed that irreversible adsorption of insoluble polymer on the GPC column, which would have changed the flow rate, did not occur during the GPC measurements. The errors of an elution count were $\pm 0.1 \mathrm{~min}$. In the conventional GPC profiles, the $\mathrm{S} / \mathrm{N}$ ratios of the elution peaks and of the baseline were checked to prevent the error in the interpretation of the 2D correlation GPC maps. The averaged $\mathrm{S} / \mathrm{N}$ ratios were 170 . The amount (100 $\mu \mathrm{L}$ of the $3 \mathrm{mg} / 5 \mathrm{~mL}$ solution) of the TESiP-PScatalyst-THF solution injected onto the GPC column $(\phi 7.5 \times 600 \mathrm{~mm})$ was controlled, so as to provide a linearly increased refractive index (RI) and linearly increased UV absorbance (360 nm (phenyl group)), measured simultaneously.

\section{D GPC Correlation Analysis}

Synchronous and asynchronous 2D GPC correlation 
spectra were calculated from the time-resolved GPC profiles. Computations were carried out using 2D OGAIZA software, ${ }^{12}$ developed by Ogasawara and Izawa at Nagoya Institute of Technology. The timeresolved GPC profiles were taken into the computer by a scanner, and the absorption intensity was quantified every fiftieth count using a coordinates analysis software. The coordinate data of the GPC profiles in each step were converted into a $2 \mathrm{D}$ correlation map by 2D OGAIZA.

\section{RESULTS}

Time-resolved GPC Elution Profiles and Kinetics

In the TESiP-PS-THF- $1 \mathrm{~mol} / \mathrm{kg} \mathrm{KOH} \cdot \mathrm{H}_{2} \mathrm{O}$ system, the reaction may be represented by the following scheme:

$$
\begin{aligned}
& \text { PS }-\mathrm{C}_{3} \mathrm{H}_{6}-\mathrm{SiR}_{2}\left(\mathrm{OCH}_{2} \mathrm{CH}_{3}\right)+\mathrm{H}_{2} \mathrm{O} \\
& \stackrel{\mathrm{KOH}}{\longrightarrow} \text { PS- } \mathrm{C}_{3} \mathrm{H}_{6}-\mathrm{SiR}_{2}(\mathrm{OH})+\mathrm{CH}_{3} \mathrm{CH}_{2} \mathrm{OH}
\end{aligned}
$$

$2 \mathbf{P S}-\mathrm{C}_{2} \mathrm{H}_{6}-\mathrm{SiR}_{2}(\mathrm{OH})$

$$
\longrightarrow \text { PS- } \mathrm{C}_{3} \mathrm{H}_{6}-\mathrm{SiR}_{2}-\mathrm{O}-\mathrm{SiR}_{2}-\mathrm{C}_{3} \mathrm{H}_{6}-\mathbf{P S}+\mathrm{H}_{2} \mathrm{O}
$$

PS: polystyrene chain

$$
\mathrm{R}:-\mathrm{OCH}_{2} \mathrm{CH}_{3},-\mathrm{OH} \text { or }-\mathrm{O}-\mathrm{Si}-
$$

Equations I and II express the reaction for hydrolysis of this polymeric SCA to its monomer and the subsequent condensation reaction of the monomers (or similarly monomer with oligomer), respectively. Condensed products are regarded as branched polymers.

In our previous paper, ${ }^{28}$ which described the condensation products of triethoxysilyl-terminated polystyrene (TESi-PS), the degree of polymerization (DP(GPC)), determined from calibration with PS standards, was compared with that obtained by vapor pressure osmometry (DP(VPO)). There was good agreement (difference $(\triangle \mathrm{DP})=0.2-0.3)$ between the DP values evaluated by the two techniques. Thus, it was confirmed that the GPC technique could be used to determine the DP values of condensed products for the TESi-PS system. Since the difference in the molecular structure between TESi-PS and TESiP-PS is only $\left(\mathrm{CH}_{2}\right)_{3}$, then we may also apply this GPC method to the TESiP-PS system under investigation herein.

Thus, in this present study, the mechanism for polymerization of TESiP-PS, catalyzed by $1 \mathrm{~mol} / \mathrm{kg}$ $\mathrm{KOH} \cdot \mathrm{H}_{2} \mathrm{O}$, has been examined using GPC.

The GPC elution profiles which were obtained dur-

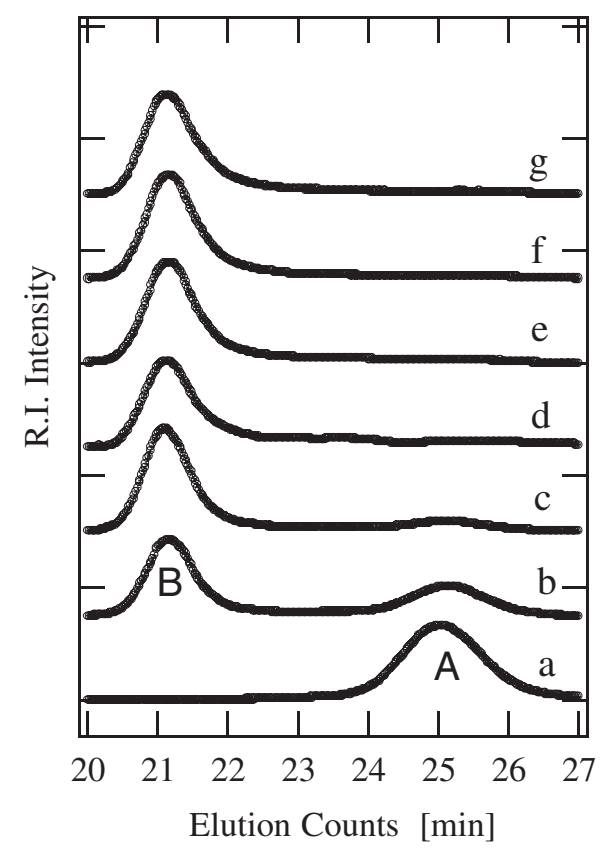

Figure 2. Time-resolved GPC elution profile of the KOH cat-

\begin{tabular}{|c|c|c|c|c|}
\hline \multicolumn{2}{|c|}{ Conventional GPC } & \multicolumn{2}{|c|}{ 2D GPC } & \multirow{2}{*}{ Assignment } \\
\hline Counts (min) & Product & Counts (min) & Band no & \\
\hline \multirow{6}{*}{25.0} & \multirow{6}{*}{ Monomer } & 26.4 & $\mathrm{~T}$ & THSiP-PS \\
\hline & & 25.2 & $\mathrm{~A}_{\mathrm{H}}$ & \multirow{2}{*}{ TESiP-PS } \\
\hline & & 25.0 & A & \\
\hline & & 24.6 & $\mathrm{~A}_{\mathrm{L}}$ & Solvated THSiP-PS \\
\hline & & 23.8 & $\mathrm{C}$ & \multirow{2}{*}{ Partially hydrolyzed dimer } \\
\hline & & 23.6 & $\mathrm{C}^{\prime}$ & \\
\hline \multirow[t]{2}{*}{23.0} & \multirow[t]{2}{*}{ Dimer } & 23.0 & $\mathrm{D}$ & Dimer \\
\hline & & 22.6 & $\mathrm{D}^{\prime}$ & Solvated dimer \\
\hline 22.0 & Trimer & 22.0 & $\mathrm{~B}_{\mathrm{H}}^{\prime}$ & Trimer \\
\hline \multirow[t]{4}{*}{21.4} & Tetramer & 21.4 & $\mathrm{~B}_{\mathrm{H}}$ & \multirow{2}{*}{ Tetramer } \\
\hline & & 21.1 & B & \\
\hline & & 20.8 & $\mathrm{~B}_{\mathrm{L}}$ & Hexamer \\
\hline & & 20.4 & $\mathrm{~B}_{\mathrm{L}}^{\prime}$ & Octamer \\
\hline
\end{tabular}
alyzed TESiP-PS-THF system at $t=(\mathrm{a}, 0 \mathrm{~h} ; \mathrm{b}, 0.5 \mathrm{~h} ; \mathrm{c}, 1.0 \mathrm{~h}$; d, 2.0 h; e, 3 h; f, 4 h; g, 24 h).

Table I. Tentative assignment of elution peaks ${ }^{\mathrm{a}}$

${ }^{\mathrm{a}}$ The errors of elution peaks are $\pm 0.1 \mathrm{~min}$. 
ing the polymerization are shown in Figure 2. Assignments of elution bands (marked with an asterisk) are listed in Table I together with those of elution bands confirmed by 2D GPC spectra (Figures 4-6). ${ }^{12,14}$

The TESiP-PS monomer (profile a) has only one elution band, A, at $25.2 \mathrm{~min}$. After $0.5 \mathrm{~h}$ reaction time (profile b), two predominant elution bands A and B appear at 25.2 and $21.2 \mathrm{~min}$, respectively. Based on the polystyrene calibration curve (Figure 1), the bands $\mathrm{A}$ and $\mathrm{B}$ can be attributed to TESiP-PS monomers and tetramers, respectively. With time, the intensity of band A decreases, while that of band B rapidly increases, indicating that consumption of TESiP-PS occurs to form the tetramers whose fraction increases with time. It was confirmed that the RI intensity of the elution band $\mathrm{B}$ at $t=24 \mathrm{~h}$ is almost equal to that at $t=4 \mathrm{~h}$. This fact implies that the polymerization reaction virtually attains equilibrium at $t=4 \mathrm{~h}$, and that the growth of polymeric aggregates beyond the tetramer does not apparently occur. That is, the results of the elution profiles indicate that preferential production of tetramers occurs in this reaction system.

For the TESiP-PS monomers, it should be possible to observe independently the elution bands of the TESiP-PS monomer and of its hydrolyzed monomer (trihydroxysilyl-propyl PS, THSiP-PS). However, in this present study, while the elution band at 25.2 min, which corresponds to unhydrolyzed TESiP-PS monomer, was found, that for the corresponding THSiP-PS monomer was not. The apparent disappearance of the THSiP-PS elution peak may come from rapid consumption of the monomer through formation of oligomers or aggregates during the base-catalyzed polymerization reaction, thereby accelerating the reaction rate. ${ }^{29} \mathrm{We}$ may assume that the elution band for the THSiP-PS species appears at a higher elution count (probably $26.4 \mathrm{~min}$ ), compared with that of TESiP-PS, since resolution enhancement of the 2D GPC spectra ${ }^{12,14}$ provides evidence that a very weak trihydrolyzed THSiP-PS band appears at $26.4 \mathrm{~min}$ (Figures 5 and 6), as noted below. For oligomers larger than the trimer, it seems to be very difficult to distinguish the extent of hydrolysis by using the RI method, since the difference in the elution count for larger oligomers becomes vanishingly small.

In our previous papers, ${ }^{12,14}$ we have examined the time-resolved GPC profiles of the $1.0 \mathrm{M} \mathrm{HCl} \cdot \mathrm{H}_{2} \mathrm{O}$ catalyzed octyltriethoxysilane (OTES) and perfluorooctyltriethoxysilane (PFOTES)-ethanol reaction mixtures in their earliest stages (initial 10 or $30 \mathrm{~min}$ ) of the polymerizations. We found that the band intensities of their trihydrolyzed monomers decreased rapidly with reaction time as they formed the polymeric precursors, until they apparently disappeared over the elapse of the sampling times. This fact implies that the reactivity of the trihydrolyzed monomeric species is very high. Furthermore, we may assume that the disappearance of the band for the trihydrolyzed species will occur more rapidly in the base-catalyzed system, since the rate of reaction for the base-catalyzed SCA is much faster than that for the acid-catalyzed system. ${ }^{30}$

However, in this present study, the GPC profiles of the base-catalyzed TESiP-PS-THF system were timeresolved over a long-time scale (the prescribed time for sampling was hourly expect for the two initial samples ( $t=0$ and $0.5 \mathrm{~h}$ respectively), possibly leading to the apparent disappearance of the TESiP-PS elution band because of the consumption of the trihydrolyzed species in the initial thirty minutes.

We have demonstrated that resolution enhancement of 2D correlation GPC provides ample evidence for the existence of extremely weak elution bands for the trihydrolyzed species of OTES ${ }^{12}$ and PFOTES, ${ }^{14}$ which were not apparent in the GPC profiles, indicating that the 2D correlation GPC technique is useful for detection of very weak elution bands.

In order to examine the kinetics of the condensation reaction for the TESiP-PS-KOH- $\mathrm{H}_{2} \mathrm{O}-\mathrm{THF}$ system, the yield $Y$ of polymerized TESiP-PS was calculated by the equation

$$
\begin{aligned}
\mathrm{Y}(\%)= & 100 \times[\text { the GPC band area of polymerized } \\
& \text { TESiP-PS }] /[\text { the total GPC band area } \\
& \text { of the reacted products }] .
\end{aligned}
$$

The reaction time dependence of the $Y$ value $(333 \mathrm{~K})$ is shown in Figure 3. It was assumed that the percentage $(Z(\%)=100-Y(\%))$ of the TESiP-PS monomers, which remained unreacted, is equal to 100 at reaction time $t=0 \mathrm{~s}$ and equal to 0 at $t=\infty$. We find that the $Y$ value increased exponentially with time while the $Z$ value decreases exponentially, indicating

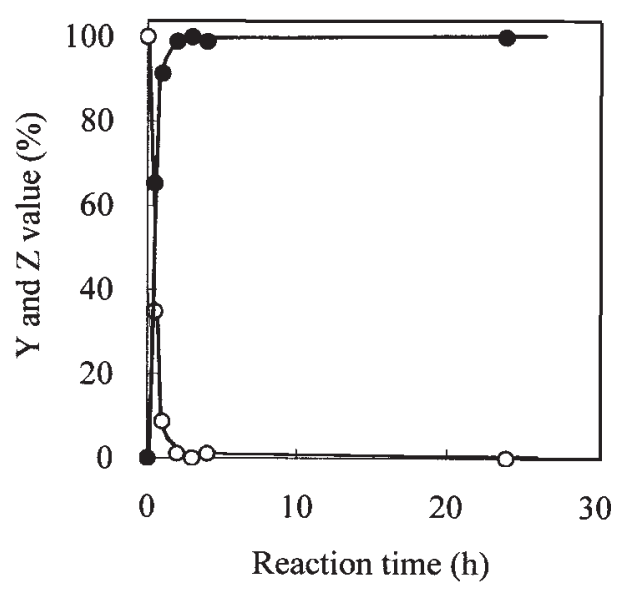

Figure 3. The reaction-time dependence of the $Y(\bullet)$ and $\mathrm{Z}$ (○) values. 


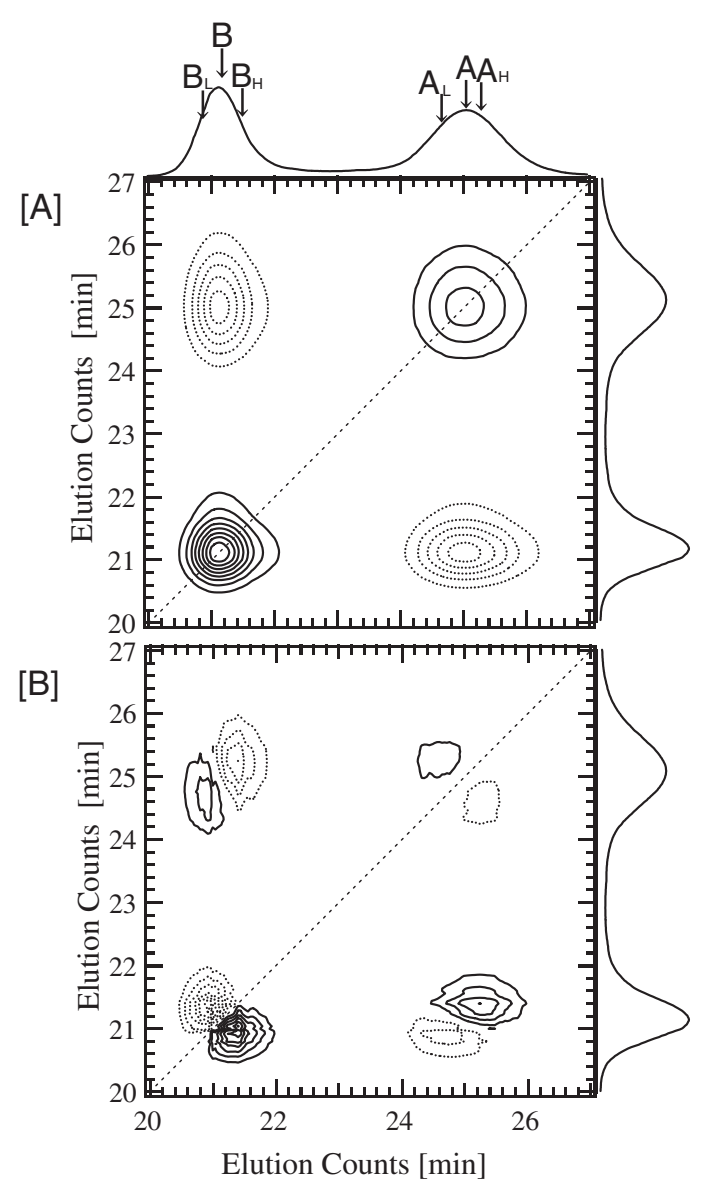

Figure 4. (A) Synchronous and (B) asynchronous spectra of step I $(0,0.5,1 \mathrm{~h})$ for the $\mathrm{KOH}$-catalyzed TESiP-PS-THF system.

that the time dependence of $Y$ and $Z$ reflects the kinetics of the base-catalyzed reaction of TESiP-PS in THF. In order to analyze these data, we assumed that the time course of $Z$ can be expressed by $Z=$ $A \exp (-k t)+B\left(A=100\right.$ and $B=0, k\left(\mathrm{~s}^{-1}\right)=$ rate constant). A plot of $Z$ (\%) vs. $t$, which provides the best fit between the observed data and the calculated values, is also shown in Figure 3. The rate constant thus obtained is $k=6.12 \times 10^{-4} \mathrm{~s}^{-1}$, which is larger than the rate constant $\left(k=1.10 \times 10^{-4} \mathrm{~s}^{-1}\right)$ obtained from the GPC data for the acid-catalyzed condensation reaction of triethoxysilyl-terminated polystyrene. $^{29}$

\section{$2 D$ Correlation GPC and Aggregate-Aggregate Cor- relations}

The synchronous and asynchronous 2D GPC correlation spectra, which were calculated directly from the set of time-dependent GPC profiles, are shown in Figure 4. Assignments of elution peaks, based on the polystyrene standard calibration, are listed in Table I. The band correlations, signs and order of events are listed in Table II. The possible synchronous correlation squares $\left(\mathrm{CSq}_{i}\right.$, where $\left.i=1-9\right)$ and
Table II. Synchronous and asynchronous correlations for the KOH catalyzed TESiP-PS-THF system-band correlations, signs and order of events

\begin{tabular}{|c|c|c|c|c|c|c|c|c|}
\hline \multirow{3}{*}{ Step } & \multirow{2}{*}{\multicolumn{3}{|c|}{ Correlation $^{\mathrm{a}}$}} & \multicolumn{2}{|c|}{ Sign } & \multirow{2}{*}{\multicolumn{3}{|c|}{ Order of events }} \\
\hline & & & & \multirow{2}{*}{$\frac{(\Phi)^{\mathrm{b}}}{+}$} & \multirow{2}{*}{$\frac{(\Psi)^{\mathrm{c}}}{-}$} & & & \\
\hline & $\mathrm{A}_{\mathrm{H}}$ & $\leftrightarrow$ & $\mathrm{A}_{\mathrm{L}}(\mathrm{w})$ & & & $A_{L}$ & $\rightarrow$ & $\mathrm{A}_{\mathrm{H}}$ \\
\hline \multirow{3}{*}{ I } & $\mathrm{A}_{\mathrm{H}}$ & $\leftrightarrow$ & $\mathrm{B}_{\mathrm{H}} \quad(\mathrm{m})$ & - & + & $\mathrm{B}_{\mathrm{H}}$ & $\rightarrow$ & $\mathrm{A}_{\mathrm{H}}$ \\
\hline & $A_{L}$ & $\leftrightarrow$ & $\mathrm{B}_{\mathrm{L}} \quad(\mathrm{m})$ & - & - & $\mathrm{A}_{\mathrm{L}}$ & $\rightarrow$ & $\mathrm{B}_{\mathrm{L}}$ \\
\hline & $\mathrm{B}_{\mathrm{H}}$ & $\leftrightarrow$ & $\mathrm{B}_{\mathrm{L}} \quad(\mathrm{s})$ & + & + & $\mathrm{B}_{\mathrm{H}}$ & $\rightarrow$ & $\mathrm{B}_{\mathrm{L}}$ \\
\hline \multirow{4}{*}{ II } & $\mathrm{A}_{\mathrm{H}}$ & $\leftrightarrow$ & $\mathrm{B}_{\mathrm{H}}(\mathrm{m})$ & + & - & $\mathrm{B}_{\mathrm{H}}$ & $\rightarrow$ & $\mathrm{A}_{\mathrm{H}}$ \\
\hline & $\mathrm{C}^{\prime}$ & $\leftrightarrow$ & $\mathrm{B}_{\mathrm{H}} \quad(\mathrm{w})$ & - & + & $\mathrm{B}_{\mathrm{H}}$ & $\rightarrow$ & $\mathrm{C}^{\prime}$ \\
\hline & $\mathrm{D}$ & $\leftrightarrow$ & $\mathrm{B}_{\mathrm{H}} \quad(\mathrm{w})$ & - & + & $\mathrm{B}_{\mathrm{H}}$ & $\rightarrow$ & $\mathrm{D}$ \\
\hline & $\mathrm{B}_{\mathrm{H}}$ & $\leftrightarrow$ & $\mathrm{B}_{\mathrm{L}} \quad(\mathrm{s})$ & + & + & $\mathrm{B}_{\mathrm{H}}$ & $\rightarrow$ & $\mathrm{B}_{\mathrm{L}}$ \\
\hline \multirow{13}{*}{ III } & $\mathrm{T}$ & $\leftrightarrow$ & $\mathrm{B}_{\mathrm{L}} \quad(\mathrm{w})$ & + & + & $\mathrm{T}$ & $\rightarrow$ & $\mathrm{B}_{\mathrm{L}}$ \\
\hline & $\mathrm{T}$ & $\leftrightarrow$ & $\mathrm{B}_{\mathrm{H}} \quad(\mathrm{m})$ & + & - & $\mathrm{B}_{\mathrm{H}}$ & $\rightarrow$ & $\mathrm{T}$ \\
\hline & $\mathrm{A}_{\mathrm{L}}$ & $\leftrightarrow$ & $\mathrm{B}_{\mathrm{L}} \quad(\mathrm{m})$ & + & - & $\mathrm{B}_{\mathrm{L}}$ & $\rightarrow$ & $A_{L}$ \\
\hline & $\mathrm{A}_{\mathrm{L}}$ & $\leftrightarrow$ & $\mathrm{B}_{\mathrm{H}} \quad(\mathrm{m})$ & + & + & $\mathrm{A}_{\mathrm{L}}$ & $\rightarrow$ & $\mathrm{B}_{\mathrm{H}}$ \\
\hline & $\mathrm{C}$ & $\leftrightarrow$ & $\mathrm{B}_{\mathrm{L}} \quad(\mathrm{m})$ & + & - & $\mathrm{B}_{\mathrm{L}}$ & $\rightarrow$ & $\mathrm{C}$ \\
\hline & $\mathrm{C}$ & $\leftrightarrow$ & $\mathrm{B}_{\mathrm{H}} \quad(\mathrm{m})$ & + & + & $\mathrm{C}$ & $\rightarrow$ & $\mathrm{B}_{\mathrm{H}}$ \\
\hline & $\mathrm{D}$ & $\leftrightarrow$ & $\mathrm{B}_{\mathrm{L}} \quad(\mathrm{w})$ & + & - & $\mathrm{B}_{\mathrm{L}}$ & $\rightarrow$ & $\mathrm{D}$ \\
\hline & $\mathrm{D}$ & $\leftrightarrow$ & $\mathrm{B}_{\mathrm{H}} \quad(\mathrm{m})$ & + & + & $\mathrm{D}$ & $\rightarrow$ & $\mathrm{B}_{\mathrm{H}}$ \\
\hline & $\mathrm{B}_{\mathrm{H}}^{\prime}$ & $\leftrightarrow$ & $\mathrm{B}_{\mathrm{L}} \quad(\mathrm{w})$ & + & + & $\mathrm{B}_{\mathrm{H}}^{\prime}$ & $\rightarrow$ & $\mathrm{B}_{\mathrm{L}}$ \\
\hline & $\mathrm{B}_{\mathrm{H}}^{\prime}$ & $\leftrightarrow$ & $\mathrm{B}_{\mathrm{H}} \quad(\mathrm{w})$ & - & - & $\mathrm{B}_{\mathrm{H}}^{\prime}$ & $\rightarrow$ & $\mathrm{B}_{\mathrm{H}}$ \\
\hline & $\mathrm{B}_{\mathrm{H}}$ & $\leftrightarrow$ & $\mathrm{B}_{\mathrm{L}}^{\prime}(\mathrm{w})$ & + & - & $\mathrm{B}_{\mathrm{L}}^{\prime}$ & $\rightarrow$ & $\mathrm{B}_{\mathrm{H}}$ \\
\hline & $\mathrm{B}_{\mathrm{H}}$ & $\leftrightarrow$ & $\mathrm{B}_{\mathrm{L}} \quad$ (s) & - & + & $\mathrm{B}_{\mathrm{L}}$ & $\rightarrow$ & $\mathrm{B}_{\mathrm{H}}$ \\
\hline & $\mathrm{B}_{\mathrm{L}}$ & $\leftrightarrow$ & $\mathrm{B}_{\mathrm{L}}^{\prime}(\mathrm{w})$ & - & + & $\mathrm{B}_{\mathrm{L}}^{\prime}$ & $\rightarrow$ & $\mathrm{B}_{\mathrm{L}}$ \\
\hline
\end{tabular}

${ }^{\mathrm{a}} \mathrm{s}$ : strong, m: medium, w: weak.

${ }^{\mathrm{b}}$ Synchronous

${ }^{\mathrm{c}}$ Asynchronous

${ }^{d} E_{x} \rightarrow E_{y}$; the event of $E_{x}$ occurs befor that of $E_{y}$.

Table III. Possible synchronous correlation squares $\left(\mathrm{CSq}_{i}: i=1-9\right)$ and band correlations

\begin{tabular}{cllll}
\hline Step & $\mathrm{CSq}_{i}$ & \multicolumn{3}{c}{ Band correlations } \\
\hline $\mathrm{I}$ & $\mathrm{CSq}_{1}$ & $\mathrm{~A}$ & $\longleftrightarrow$ & $\mathrm{B}$ \\
\hline & $\mathrm{CSq}_{2}$ & $\mathrm{~A}$ & $\longleftrightarrow$ & $\mathrm{B}_{\mathrm{H}}$ \\
& $\mathrm{CSq}_{3}$ & $\mathrm{~A}$ & $\longleftrightarrow$ & $\mathrm{B}_{\mathrm{L}}$ \\
& $\mathrm{CSq}_{4}$ & $\mathrm{C}$ & $\longleftrightarrow$ & $\mathrm{D}$ \\
$\mathrm{II}$ & $\mathrm{CSq}_{5}$ & $\mathrm{C}$ & $\longleftrightarrow$ & $\mathrm{B}_{\mathrm{L}}$ \\
& $\mathrm{CSq}_{6}$ & $\mathrm{D}$ & $\longleftrightarrow$ & $\mathrm{B}_{\mathrm{H}^{\prime}}$ \\
& $\mathrm{CSq}_{7}$ & $\mathrm{D}$ & $\longleftrightarrow$ & $\mathrm{B}_{\mathrm{L}}$ \\
& $\mathrm{CSq}_{8}$ & $\mathrm{~B}_{\mathrm{H}}$ & $\longleftrightarrow$ & $\mathrm{B}_{\mathrm{L}}$ \\
\hline $\mathrm{III}$ & $\mathrm{CSq}_{9}$ & $\mathrm{~B}_{\mathrm{H}}$ & $\longleftrightarrow$ & $\mathrm{B}_{\mathrm{L}}$ \\
\hline
\end{tabular}

their corresponding band correlations are listed in Table III.

In the synchronous map (step I) (Figure 4A), the strong intensity of the autopeak B at 21.1 min suggests that the tetramers are rapidly produced in this process. The negative cross peaks (located at the off diagonal positions $(\mathrm{A} \leftrightarrow \mathrm{B})$ and $(\mathrm{B} \leftrightarrow \mathrm{A})$, where $\mathrm{A} \neq \mathrm{B})$, such as those at $(25.0,21.1)$ and $(21.1,25.0)$ arise from the coordinated decrease in intensity of band $\mathrm{A}$ and simultaneous increase in intensity of band $\mathrm{B}$, showing 


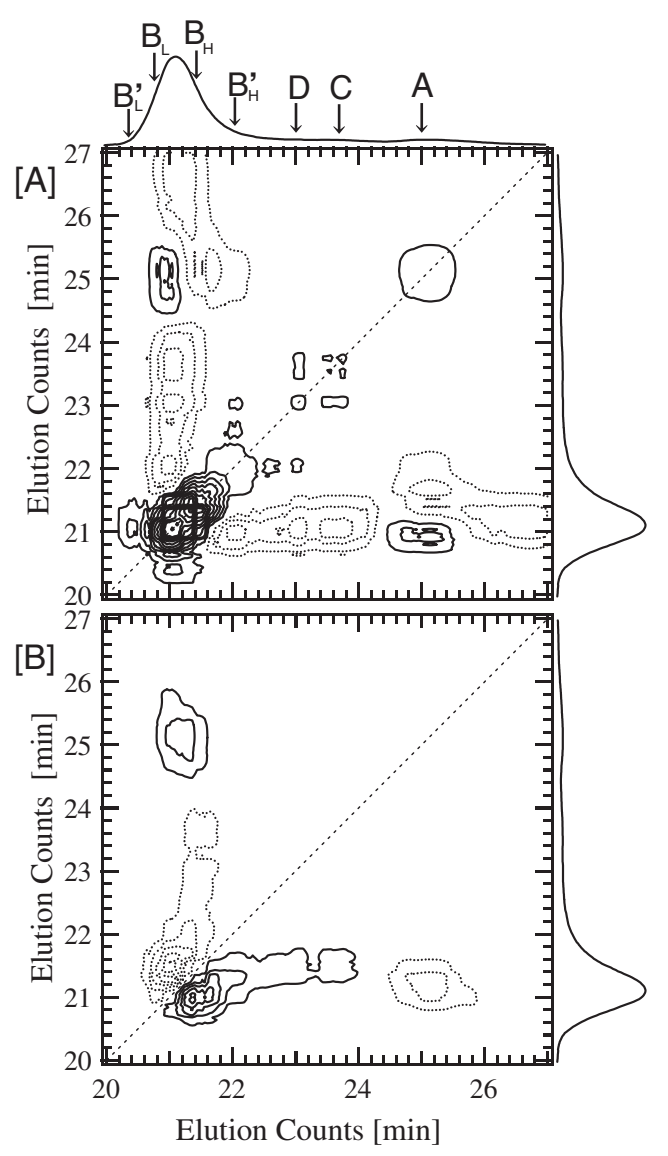

Figure 5. (A) Synchronous and (B) asynchronous spectra of step II (1, 2, $3 \mathrm{~h}$ ) for the $\mathrm{KOH}$-catalyzed TESiP-PS-THF system.

directly the existence of coherent variation of GPC trace intensities at these elution times which are reflected in the $\mathrm{CSq}_{1}$.

In the asynchronous spectrum (step I) (Figure 4B), it is found that each of bands $A$ and $B$ consists of two components $\left(\mathrm{A}_{\mathrm{H}}\right.$ and $\mathrm{A}_{\mathrm{L}}$ and $\mathrm{B}_{\mathrm{H}}$ and $\mathrm{B}_{\mathrm{L}}$, respectively) detected by the resolution enhancing characteristics of the 2D GPC spectra. The positive cross peak arising from the $A_{H} \leftrightarrow A_{L}$ correlation indicates directly that the $A_{L}$ component changes first and is followed by the $A_{H}$ component change. The two components, $A_{H}$ and $A_{L}$, correlate with two other components, $B_{H}$ and $\mathrm{B}_{\mathrm{L}}$, respectively. In step $\mathrm{I}$, the $\mathrm{A}_{\mathrm{H}} \leftrightarrow \mathrm{B}_{\mathrm{H}}$ correlation brings about one positive cross peak, while the $\mathrm{A}_{\mathrm{L}} \leftrightarrow \mathrm{B}_{\mathrm{L}}$ correlation provides one negative cross peak, implying that the $\mathrm{B}_{\mathrm{H}}$ (or $\mathrm{A}_{\mathrm{L}}$ ) component changes first and then the $\mathrm{A}_{\mathrm{H}}$ (or $\mathrm{B}_{\mathrm{L}}$ ) component changes. ${ }^{2,3}$ It should be noted in step I that both components $\mathrm{B}_{\mathrm{H}}$ (tetramer) and $\mathrm{B}_{\mathrm{L}}$ (hexamer) are rapidly produced as a consequence of consumption of components $\mathrm{A}_{\mathrm{H}}$ and $\mathrm{A}_{\mathrm{L}}$.

In the synchronous map (step II) (Figure 5A), four autopeaks are newly observed at 21.5, 22.0, 23.0 and $23.8 \mathrm{~min}$, in addition to the autopeaks at 21.1 and $25.2 \mathrm{~min}$. In particular, the existence of the autopeaks at 21.1, 21.5 and 22.0 min indicates that band $\mathrm{B}$ consists of three different components $\left(\mathrm{B}_{\mathrm{L}}, \mathrm{B}_{\mathrm{H}}\right.$ and $\left.\mathrm{B}_{\mathrm{H}}{ }^{\prime}\right)$ in step II. The very strong intensities of the autopeaks at 21.1 and $21.5 \mathrm{~min}$ indicate directly that the intensities of the $\mathrm{B}_{\mathrm{L}}$ and $\mathrm{B}_{\mathrm{H}}$ components vary rapidly with reaction time. The positive and negative cross peaks at $(25.2,21.0)$ and $(25.2,21.7)$ imply that band $B$ is composed mainly of two different components $\left(\mathrm{B}_{\mathrm{L}}\right.$ and $\mathrm{B}_{\mathrm{H}}$ ) whose intensities change in opposite directions. That is, in step II, the $\mathrm{B}_{\mathrm{H}}$ component increases, while the $\mathrm{B}_{\mathrm{L}}$ component decreases. The cross peaks at $(22.0,21.0),(23.0,21.0)$ and $(23.8,21.0)$, which arise from the correlations of elution bands $\mathrm{B}_{\mathrm{H}}{ }^{\prime}, \mathrm{D}$ and $\mathrm{C}$, respectively with the $\mathrm{B}_{\mathrm{L}}$ component, are negative, reflecting the increased intensity variations of the $\mathrm{B}_{\mathrm{H}}{ }^{\prime}$, $\mathrm{D}$ and $\mathrm{C}$ bands. Conversely, positive $\left(\mathrm{B}_{\mathrm{L}} \leftrightarrow \mathrm{B}_{\mathrm{L}}{ }^{\prime}\right)$, $\left(\mathrm{D} \leftrightarrow \mathrm{B}_{\mathrm{H}}{ }^{\prime}\right)$ and $(\mathrm{C} \leftrightarrow \mathrm{D})$ cross peaks, which are at $(21.1,20.4),(23.0,22.0)$ and $(23.8,23.0)$, respectively, reflect the decreased intensity variations of the elution bands $\mathrm{B}_{\mathrm{L}}, \mathrm{D}$ and $\mathrm{C}$. When we compare the intensity of the $\mathrm{B}_{\mathrm{H}}\left(\right.$ or $\mathrm{B}_{\mathrm{L}}$ ) autopeak with that of the $\mathrm{C}$ (or $\mathrm{D}$ or $\mathrm{B}_{\mathrm{H}}{ }^{\prime}$ ) autopeaks in the synchronous spectrum (step II), we find that the intensity of the former autopeak is greater than those of the latter. This fact implies that the $\mathrm{B}_{\mathrm{H}}$ (or $\mathrm{B}_{\mathrm{L}}$ ) component contributes to a major extent to the polymerization process, indicating that the intensity variation of the $\mathrm{B}_{\mathrm{H}}$ and $\mathrm{B}_{\mathrm{L}}$ components occurs rapidly in step II.

In the asynchronous spectrum (step II) (Figure 5B), the correlations of band $\mathrm{B}_{\mathrm{H}}$ with band $\mathrm{A}_{\mathrm{H}}$ and $\mathrm{B}_{\mathrm{L}}$ provide the negative and positive cross peaks at coordinates $(25.2,21.2)$ and $(21.5,21.0)$, respectively. The negative cross peak implies that the $\mathrm{A}_{\mathrm{H}}$ components are consumed to produce the $\mathrm{B}_{\mathrm{H}}$ component. The relatively strong positive cross peak indicates that, as a consequence of consumption of the $\mathrm{A}_{\mathrm{H}}$ component, rapid production of the $\mathrm{B}_{\mathrm{H}}$ components occurs. The correlations of band $\mathrm{B}_{\mathrm{H}}$ with bands $\mathrm{C}, \mathrm{D}$ and $\mathrm{B}_{\mathrm{H}}{ }^{\prime}$ also provide the positive cross peaks at coordinates $(23.6,21.5)$ and $(22.0-23.0,21.5)$, which arise from the production of the $\mathrm{B}_{\mathrm{H}}$ component accompanying the consumption of the $\mathrm{C}$ and $\mathrm{D}$ components.

The synchronous spectrum in step III is shown in Figure 6A. In the region $E_{1}=E_{2}=20-22$, the $\mathrm{B}_{\mathrm{H}} \leftrightarrow$ $\mathrm{B}_{\mathrm{L}}$ correlation provides two autopeaks and two negative cross peaks which construct a small correlation square $\left(\mathrm{CSq}_{9}\right)$ (Table III). Since we may assume the existence of a very weak autopeak coming from component $\mathrm{B}_{\mathrm{H}}{ }^{\prime}$ (or $\mathrm{B}_{\mathrm{L}}{ }^{\prime}$ ), we may construct a correlation square by connecting the $\mathrm{B}_{\mathrm{H}}{ }^{\prime}$ and $\mathrm{B}_{\mathrm{L}}{ }^{\prime}$ autopeaks with two negative cross peaks. However, the $\mathrm{B}_{\mathrm{H}} \leftrightarrow \mathrm{B}_{\mathrm{L}}$ correlation contributes predominately to the polymerization process.

In the asynchronous map (step III) (Figure 6B), in particular, we find that the $\mathrm{B}_{\mathrm{H}} \leftrightarrow \mathrm{B}_{\mathrm{L}}$ correlation is 


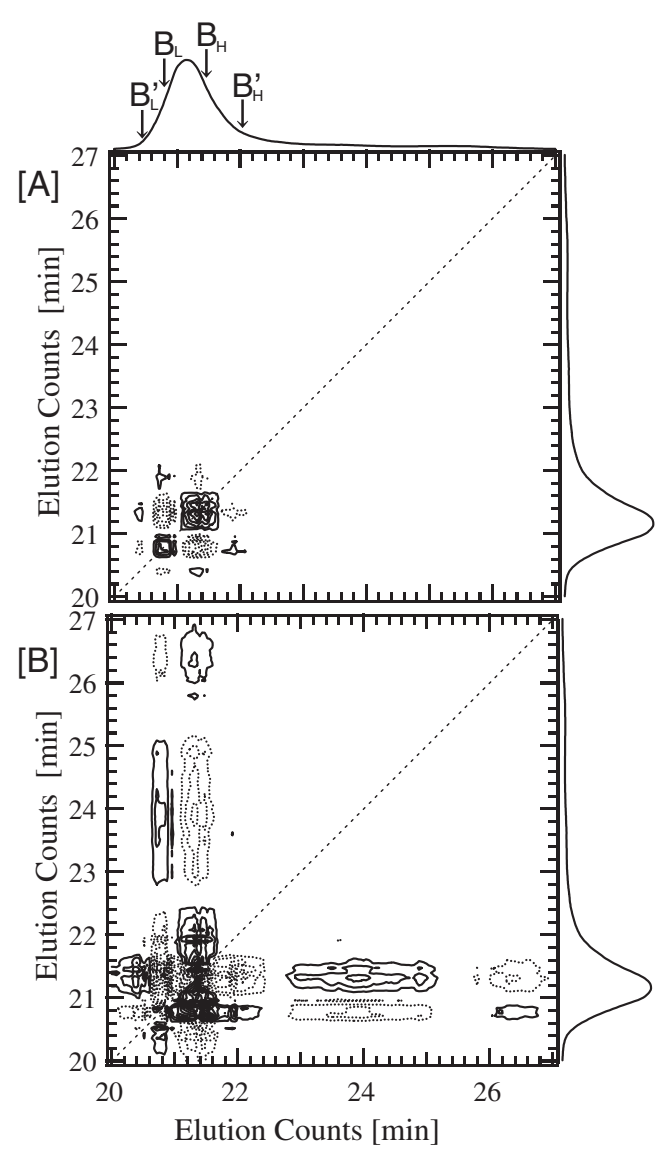

Figure 6. (A) Synchronous and (B) asynchronous spectra of step III $(3,4,24 \mathrm{~h})$ for the KOH-catalyzed TESiP-PS-THF system.

predominant in step III. The components $\mathrm{A}_{\mathrm{L}}, \mathrm{C}$ and $\mathrm{D}$ also correlate with the $\mathrm{B}_{\mathrm{H}}$ and $\mathrm{B}_{\mathrm{L}}$ components, implying that the monomers and smaller oligomers also contribute to formation of the $\mathrm{B}_{\mathrm{H}}$ and $\mathrm{B}_{\mathrm{L}}$ components in step III. Furthermore, we note the appearance of the cross peaks at $(26.4,20.8)$ and $(26.4,21.4)$, which may arise from the correlations between the THSiP-PS monomers and the $\mathrm{B}_{\mathrm{L}}$ and $\mathrm{B}_{\mathrm{H}}$ components. The result indicates that the hydrolysis products (THSiP-PS) contribute to formation of the $\mathrm{B}_{\mathrm{H}}$ and $\mathrm{B}_{\mathrm{L}}$ components in step III, although only to a small extent.

\section{DISCUSSION}

Recently, we examined the rate of the acid-catalyzed condensation of five well-defined polymeric silane coupling agents, triethoxysilyl-terminated polystyrene (TESi-PS), substituted with a polystyrene moiety of various molecular weights. ${ }^{29}$

We summarize the important findings below.

1) Investigation of the effect of the molecular weight of TESi-PS monomer on the yield of its condensed product found that a high molecular weight TESi-PS monomer led to acceleration of the condensation rate.

2) When PS molecules of various molecular weight were added to the reaction system, in order to understand the role of the PS moiety of a TESi-PS monomer, it was found that added PS accelerates the rate of condensation, implying that the PS moiety plays a critical role in acceleration of the TESi-PS condensation.

3) Determination of the effect of the addition of ethyl-benzene (EB), which can be regarded as a model-compound for a styrene unit, revealed the existence of an EB effect that accelerated the reaction rate.

The kinetic data provided irrefutable evidence that formation of aggregates during the condensation reaction accelerates the reaction rate. An aggregational model, in which the ethoxysilyl groups are concentrated in the polar core, was presented to explain the acceleration effect. This model may be applied to the polymerization process of the $\mathrm{KOH}$-catalyzed TESiP-PS-THF system, since formation of TESiPPS aggregates is also possible in THF.

Izawa et al. ${ }^{12,31}$ used time-resolved small-angle $\mathrm{X}$ ray scattering spectra to detect the aggregates of $n$ alkylalkoxides in ethanol. The results led to an aggregational model, in which a small $\mathrm{Si}-\mathrm{O}-\mathrm{Si}$ bonding network structure is formed initially by condensation between silanol groups, and this network then expands to become the core of a larger particle with extending hydrophobic chains.

Thus, we may assume that TESiP-PS aggregates, in which the triethoxysilyl groups are incorporated into the polar core, are formed predominantly even in THF solution in the absence of $\mathrm{KOH}$ catalyst. When the catalyst $\mathrm{KOH}-\mathrm{H}_{2} \mathrm{O}$ solution is added to the TESiP-PS aggregate system (step I), the $\mathrm{KOH}$ solution will probably be incorporated into the polar core, thereby initiating the polymerization reaction. When the hydrolysis of ethoxysilyl groups occurs, the aggregational effect should probably reflect the synchronous and asynchronous maps.

From the synchronous map (Figure 4A) for step I, consumption of the TESiP-PS monomers (A) apparently brings about formation of the tetramers (B). However, resolution enhancement of the asynchronous spectrum provides direct evidence that the two components $A_{H}$ and $A_{L}$ are produced in this step and that both components $\mathrm{B}_{\mathrm{L}}$ (hexamer) and $\mathrm{B}_{\mathrm{H}}$ (tetramer) are produced rapidly as a consequence of the consumption of the $A_{L}$ and $A_{H}$ components. The elution count of component $A_{H}$ is 25.3 , which is very close to that (25.2) of the TESiP-PS monomer. Therefore, this component may be assigned to the unhydrolyzed or partially hydrolyzed monomers. We may assume that the component $A_{L}$ at 24.6 min arises from the solvated 
THSiP-PS monomers, in which the ether-oxygen atom of a THF molecule forms a complex with the $\mathrm{SiOH}$ groups through a hydrogen bond. ${ }^{13}$ That is, this component from the THF-solvated complex, may be relatively reactive compared with TESiP-PS. Thus, the component $\mathrm{A}_{\mathrm{H}}$ may give rise to more unreacted ethoxy groups, compared with that of $\mathrm{A}_{\mathrm{L}}$.

The elution band arising from the THSiP-PS monomers is probably located at a higher elution time (26-27 $\mathrm{min})$. We may assume that the more reactive THSiP-PS monomers were mostly consumed by formation of oligomers and that the elution band of those monomers remaining unreacted must be very weak, leading to the apparent disappearance of the elution peak of the THSiP-PS monomers in the elution profile. However, resolution enhancement of the asynchronous spectrum provides evidence for the existence of a very weak elution band for these monomers. In the synchronous and asynchronous maps (step I) (Figure 4A and B), the $\mathrm{A}_{\mathrm{H}} \leftrightarrow \mathrm{B}_{\mathrm{H}}$ and $\mathrm{A}_{\mathrm{L}} \leftrightarrow$ $\mathrm{B}_{\mathrm{L}}$ correlations imply that consumption of the $\mathrm{B}_{\mathrm{H}}$ component brings about formation of the $\mathrm{A}_{\mathrm{H}}$ component, while the $A_{L}$ component is consumed to form the $\mathrm{B}_{\mathrm{L}}$ component.

In step II, it should be emphasized that a coordinated decrease in band $\mathrm{B}_{\mathrm{L}}$ (hexamer) and simultaneous increase in band $\mathrm{B}_{\mathrm{H}}$ (tetramer) occur. Furthermore, we note the existence of cross peaks at $(21.1,20.4)$ and $(20.1,21.4)$ (Figure 5). Since the elution count at 20.4 corresponds to an octamer, it is evident that the $\mathrm{B}_{\mathrm{H}} \leftrightarrow \mathrm{B}_{\mathrm{L}}^{\prime}$ cross peak at $(21.1,20.4)$ arises from the correlation between tetramer and octamer. This correlation indicates that the octamers $\left(\mathrm{B}_{\mathrm{L}}{ }^{\prime}\right)$ are produced from reaction or interactions between the tetramers $\left(\mathrm{B}_{\mathrm{H}}\right)$. In the synchronous spectrum (step II), correlations exist between components of small oligomers (bands $\mathrm{C}, \mathrm{D}$ and $\mathrm{B}_{\mathrm{H}}{ }^{\prime}$ ) and larger oligomers $\left(\mathrm{B}_{\mathrm{L}}\right.$ or $\left.\mathrm{B}_{\mathrm{H}}\right)$ (Table III). These correlations imply that small oligomers also contribute to formation of the $\mathrm{B}_{\mathrm{L}}$ or $\mathrm{B}_{\mathrm{H}}$ components in step II, although only to a small extent.

The synchronous spectrum for step III (Figure 6A) provides significant information on the aggregational behavior. In particular, we note the negative cross peaks at $(20.8,20.4),(21.4,20.8)$ and $(21.9,21.4)$ and the two positive peaks at $(21.4,20.4)$ and $(21.9$, 20.8). The negative $\mathrm{B}_{\mathrm{H}} \leftrightarrow \mathrm{B}_{\mathrm{L}}$ correlation arises from the coordinated increase in component $\mathrm{B}_{\mathrm{H}}$ (tetramer) and simultaneous decrease in the $\mathrm{B}_{\mathrm{L}}$ component (hexamer). Similarly, the negative $\mathrm{B}_{\mathrm{L}} \leftrightarrow \mathrm{B}_{\mathrm{L}}{ }^{\prime}$ and $\mathrm{B}_{\mathrm{H}}{ }^{\prime} \leftrightarrow$ $\mathrm{B}_{\mathrm{H}}$ cross peaks reflect the increasing population of component $\mathrm{B}_{\mathrm{L}}$ or $\mathrm{B}_{\mathrm{H}}{ }^{\prime}$ and simultaneous decrease in the $\mathrm{B}_{\mathrm{L}}{ }^{\prime}$ or $\mathrm{B}_{\mathrm{H}}$ component. However, the very strong intensity of the $\mathrm{B}_{\mathrm{H}} \leftrightarrow \mathrm{B}_{\mathrm{L}}$ correlation indicates that the contribution of this correlation to the reaction or inter- action process in step III is greater than those of the other two correlations. Conversely, the positive $\mathrm{B}_{\mathrm{H}} \leftrightarrow$ $\mathrm{B}_{\mathrm{L}}{ }^{\prime}$ and $\mathrm{B}_{\mathrm{H}}{ }^{\prime} \leftrightarrow \mathrm{B}_{\mathrm{L}}$ correlations imply a simultaneous increasing population of component $\mathrm{B}_{\mathrm{L}}{ }^{\prime}$ or $\mathrm{B}_{\mathrm{H}}{ }^{\prime}$ and decreasing population of component $\mathrm{B}_{\mathrm{H}}$ or $\mathrm{B}_{\mathrm{L}}$.

For understanding the $\mathrm{B}_{\mathrm{H}} \leftrightarrow \mathrm{B}_{\mathrm{L}}$ correlation in step I, the $\mathrm{B}_{\mathrm{H}} \leftrightarrow \mathrm{B}_{\mathrm{L}}{ }^{\prime}$ correlations in step II, and the five correlations among the components $\mathrm{B}_{\mathrm{H}}, \mathrm{B}_{\mathrm{H}}{ }^{\prime}, \mathrm{B}_{\mathrm{L}}$ and $\mathrm{B}_{\mathrm{L}}{ }^{\prime}$ in step III, we assume cascade steps between the oligomers as follows.

$$
\begin{aligned}
& \text { tetramer }\left(\mathbf{B}_{\mathrm{H}}\right) \stackrel{\rightarrow}{\longleftarrow} \text { hexamer }\left(\mathbf{B}_{\mathrm{L}}\right) \text { step I } \\
& \text { tetramer }\left(\mathbf{B}_{\mathbf{H}}\right) \underset{\leftarrow}{\operatorname{octamer}}\left(\mathbf{B}_{\mathbf{L}}{ }^{\prime}\right) \quad \text { step II } \\
& \text { trimer }\left(\mathrm{B}_{\mathrm{H}}{ }^{\prime}\right) \stackrel{\rightarrow}{\longleftarrow} \text { hexamer }\left(\mathrm{B}_{\mathrm{L}}\right) \\
& \text { trimer }\left(\mathrm{B}_{\mathrm{H}}{ }^{\prime}\right) \rightleftarrows \text { tetramer }\left(\mathrm{B}_{\mathrm{H}}\right) \\
& \text { tetramer }\left(\mathrm{B}_{\mathrm{H}}\right) \longrightarrow \text { octamer }\left(\mathrm{B}_{\mathrm{L}}{ }^{\prime}\right) \\
& \text { tetramer }\left(B_{H}\right) \stackrel{\rightarrow}{\longleftarrow} \text { hexamer }\left(B_{L}\right) \\
& \text { hexamer }\left(\mathrm{B}_{\mathrm{L}}\right) \stackrel{\rightarrow}{\longleftarrow} \operatorname{octamer}\left(\mathrm{B}_{\mathrm{L}}{ }^{\prime}\right)
\end{aligned}
$$

These cascade steps probably lie well towards the direction of the long arrow. In particular, the cascade step (d) may be predominant in step III, since the correlation $\left(\mathrm{B}_{\mathrm{H}} \leftrightarrow \mathrm{B}_{\mathrm{L}}\right)$ has a strong intensity. On the whole, there is a simultaneous increase in population of the tetramers and decrease in that of the hexamer.

Furthermore, in order to explain such a preferential production of the tetramer and hexamer in step I, the coordinated increase of the tetramer and simultaneous decrease of the hexamer in step II, and the correlations among oligomers $\left(\mathrm{B}_{\mathrm{H}}, \mathrm{B}_{\mathrm{L}}, \mathrm{B}_{\mathrm{H}}{ }^{\prime}\right.$ and $\left.\mathrm{B}_{\mathrm{L}}{ }^{\prime}\right)$ (in particular, the predominant $\mathrm{B}_{\mathrm{H}} \leftrightarrow \mathrm{B}_{\mathrm{L}}$ correlation) in step III, we now present cyclic models of the trimer and tetramer, for which growth through siloxane bonds never occurs.

When the TESiP-PS molecules form the reversed micellar-type aggregates in THF, in which the triethoxysilyl groups are concentrated in the polar core, the steric hindrance of the PS moieties probably arrests an increase in aggregation number $(N)$ beyond $N=3-4$. The polymerization reaction in the polar core region may lead to formation of cyclic trimers and tetramers with siloxane linkages and unreacted ethoxy groups in the core. However, for larger oligomers, we assume that the hexamer and octamer may be regarded as aggregates consisting of monomers, dimers, trimers or tetramers. This assumption is based on the following evidence.

In general, in the earlier polymerization process of silicic acid monomers, $\mathrm{Si}(\mathrm{OH})_{4}$, the condensation reaction leads quickly to ring structures (e.g., the cyclic tetramer), ${ }^{30,32}$ which condense internally to a 
Table IV. Possible types ${ }^{\text {a }}$ of oligomers and their aggregates

\begin{tabular}{ccc}
\hline \multirow{2}{*}{ Oligomer } & \multicolumn{2}{c}{ Types } \\
\cline { 2 - 3 } & Type 1 & Type 2 \\
\hline Trimer & cyclic 3-mer & linear 3-mer \\
\hline $\begin{array}{c}\text { Tetramer } \\
\text { (4-mer) }\end{array}$ & cyclic 4-mer & aggregate \\
\hline $\begin{array}{c}\text { Hexamer } \\
\text { (6-mer) }\end{array}$ & aggregate & (cyclic 3-mer + 1-mer) \\
\hline $\begin{array}{c}\text { Octamer } \\
\text { (8-mer) }\end{array}$ & (cyclic 4-mer + linear 2-mer) & aggregate \\
\hline
\end{tabular}

a 1-mer: monomer, 2-mer: dimer, 3-mer: trimer, 4-mer: tetramer

compact state with the $\mathrm{SiOH}$ groups remaining on the surface. This concept may be modified to conform to the growth process of the polymeric aggregates of TESiP-PS.

In the case of the hydrolyzed TESiP-PS (i.e., THSiP-PS) molecule, extremely bulky, rigid and rodlike PS chains probably hinder the three-dimensional growth of the siloxane bond network. This steric hindrance may induce the formation of cyclic structures, which are limited in size. ${ }^{31}$ Moreover, the dimeric polymer of triethoxysilyl-terminated polystyrene (TESi-PS) is reversibly hydrolyzed to provide monomeric TESi-PS, which can condense with the dimer to yield the trimer. ${ }^{31}$ However, the trimerically condensed TESi-PS, ${ }^{33}$ and in particular, the oligomers with a cyclic structure ${ }^{30}$ undergo almost no hydrolysis. Therefore, we may assume that short linear oligomers are relatively easily hydrolyzed, compared with the cyclic oligomers.

Table IV lists possible structural types of trimer, tetramer, hexamer and octamer. We assume that the aggregation between the monomer and cyclic trimer provides the type 2-tetramer and that the hexamer and octamer are formed by aggregation among smaller oligomers containing cyclic structures. Such aggregation may be induced by the hydrophobic PS-PS interactions through stacking of benzene rings (Figure 7), since it has already been confirmed that added PS (regardless of its molecular weight) and added ethylbenzene accelerate the rate of condensation. ${ }^{29}$ When the condensation reaction occurs within the aggregate, dissociation probably does not occur (Figure 7a); conversely, in the absence of this condensation, the aggregate dissociates into its constituent oligomers (Figure 7b).

Thus, the correlation $\mathrm{B}_{\mathrm{H}} \leftrightarrow \mathrm{B}_{\mathrm{L}}$ in step 1 may arise from dissociation of the type 1 hexamer aggregate (Figure 8a), while the aggregation of two major cyclic 4-mers may provide the tetramer $\leftrightarrow$ octamer $\left(\mathrm{B}_{\mathrm{H}} \leftrightarrow\right.$ $\mathrm{B}_{\mathrm{L}}{ }^{\prime}$ ) correlation in step II (Figure 8b). The strong correlation $\left(\mathrm{B}_{\mathrm{H}} \leftrightarrow \mathrm{B}_{\mathrm{L}}{ }^{\prime}\right)$ in step III may reflect the increas- (a)
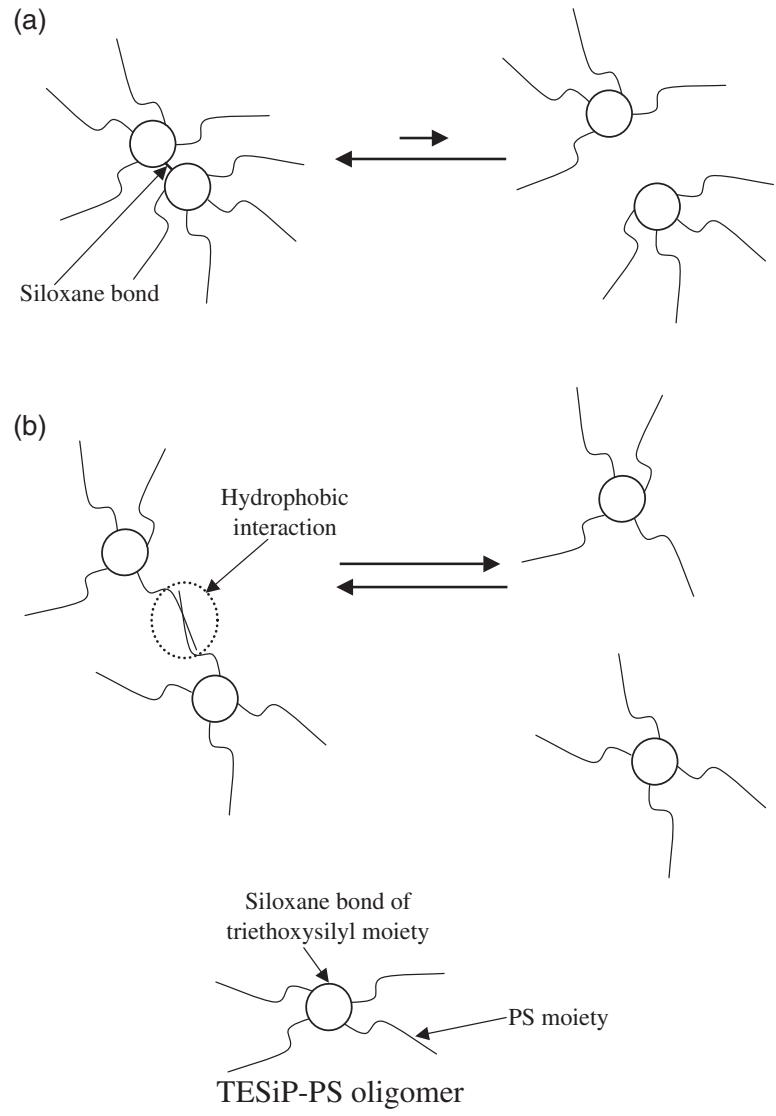

Figure 7. Schematic models of aggregates in the condensation process of TESiP-PS. (a) Preferential stabilization of the condensed aggregate; (b) dissociation of aggregate in the absence of condensation.

ed population of the tetramer which arises from dissociation of the type 1 hexamer aggregate (Figure 8a). The correlations $\left(\mathrm{B}_{\mathrm{H}}{ }^{\prime} \leftrightarrow \mathrm{B}_{\mathrm{L}}\right), \quad\left(\mathrm{B}_{\mathrm{H}}{ }^{\prime} \leftrightarrow \mathrm{B}_{\mathrm{H}}\right) \quad$ and $\left(\mathrm{B}_{\mathrm{L}} \leftrightarrow \mathrm{B}_{\mathrm{L}}{ }^{\prime}\right)$ in step III probably arise from type 2 aggregates of the hexamer, tetramer and octamer, respectively. However, since these correlation peaks are weak in intensity, the populations of the type 2 aggregates may not be high. On the whole, the contribution of type 1 aggregates to the aggregational process seems to be predominant. 
(a) type 1 hexamer

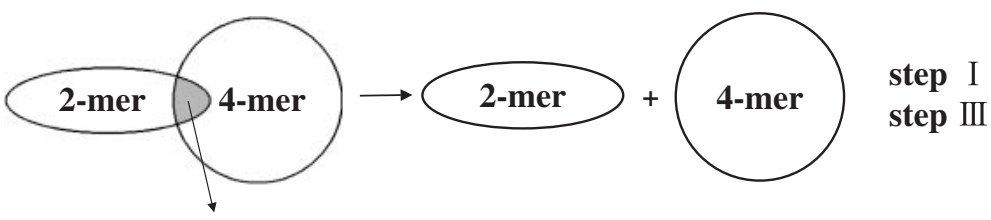

Hydrophobic interaction

(b) type 1 octamer

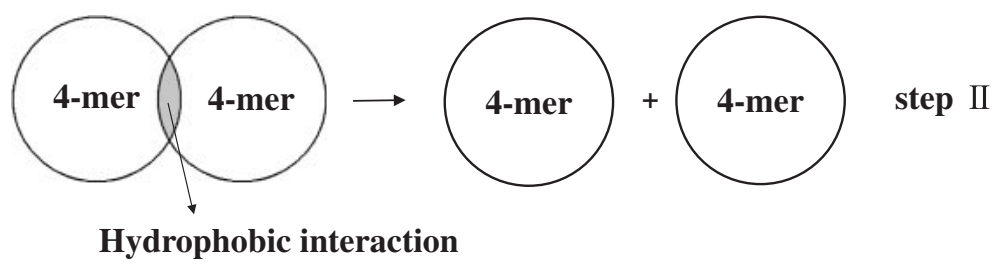

Figure 8. Schematic models of preferential stabilization of the tetramer.

\section{CONCLUSIONS}

The origin for preferential production of the tetramer in the $\mathrm{KOH}$-catalyzed polymerization of TESiPPS has been examined in detail by the use of 2D GPC correlation analysis. The results have demonstrated that the features of 2D correlation GPC spectra reflect directly the dynamic variation of the aggregational process of the polymeric silane coupling agent. In particular, formation of the aggregates among the cyclic oligomeric molecules, through hydrophobic interactions between PS chains, plays a critical role in preferential production of the tetramer. Thus, the results demonstrate the promising potential for the application of 2D correlation GPC method for examination of the aggregate-aggregate correlation or interaction in other aggregate systems, including, e.g., proteins.

\section{REFERENCES}

1. I. Noda, Appl. Spectrosc., 44, 550 (1990).

2. I. Noda, Appl. Spectrosc., 47, 1329 (1993).

3. I. Noda, A. E. Dowrey, C. Marcott, G. M. Story, and Y. Ozaki, Appl. Spectrosc., 54, 236a (2000).

4. I. Noda, Y. Liu, Y. Ozaki, and M. Czarnecki, J. Phys. Chem., 99, 3068 (1995).

5. I. Noda, Y. Liu, and Y. Ozaki, J. Phys. Chem., 100, 8674 (1996).

6. Y. Ozaki, Y. Liu, and I. Noda, Macromolecules, 30, 2391 (1997).

7. Y. Ren, M. Shimoyama, T. Ninomiya, K. Matsukawa, H. Inoue, I. Noda, and Y. Ozaki, J. Phys. Chem. B, 103, 6475 (1999).

8. N. L. Sefara, N. P. Magtoto, and H. H. Richardson, Appl. Spectrosc., 51, 536 (1997).
9. T. Ogasawara, A. Nara, H. Okabayashi, E. Nishio, and C. J. O'Connor, Colloid Polym. Sci., 278, 1070 (2000).

10. K. Izawa, T. Ogasawara, H. Masuda, H. Okabayashi, and I. Noda, PhysChemComm, 12, 1 (2001).

11. K. Izawa, T. Ogasawara, H. Masuda, H. Okabayashi, C. J. O'Connor, and I. Noda, PhysChemComm, 2, 1 (2002).

12. K. Izawa, T. Ogasawara, H. Masuda, H. Okabayashi, and I. Noda, Macromolecules, 35, 92 (2002).

13. K. Izawa, T. Ogasawara, H. Masuda, H. Okabayashi, C. J. O'Connor, and I. Noda, Phys. Chem. Chem. Phys., 4, 1053 (2002).

14. K. Izawa, T. Ogasawara, H. Masuda, H. Okabayashi, C. J. O'Connor, and I. Noda, J. Phys. Chem. B, 106, 2867 (2002).

15. H. C. Shmit, Chromatographia, 3, 515 (1970).

16. J. B. Philips and M. F. Burke, J. Chromatogr. Sci., 4, 495 (1976).

17. M. Kaljurand and E. Küllik, J. Chromatgr., 186, 145 (1979).

18. R. Annino and L. E. Bullock, Anal. Chem., 45 (1973).

19. A. Munir and E. J. Goethals, Makromol. Chem., Rapid Commun., 2, 693 (1981).

20. K. W. Lee and T. J. MacCarthy, Macromolecules, 21, 3353 (1988).

21. Y. Chujo, E. Ihara, H. Ihara, and T. Saegusa, Macromolecules, 22, 2040 (1989).

22. T. H. Mourey, S. M. Miller, J. A. Wesson, T. E. Long, and L. W. Kelts, Macromolecules, 25, 45 (1992).

23. F. Surivet, T. M. Lam, J. P. Pascault, and Q. T. Pham, Macromolecules, 25, 4309 (1992).

24. E. Nishio, N. Ikuta, H. Okabayashi, and R. W. Hannah, Appl. Spectrosc., 44, 614 (1990).

25. L. J. Fetters, N. P. Balsara, J. S. Huang, H. Jeon, K. Almdal, and M. Y. Lin, Macromolecules, 28, 4996 (1995).

26. J. Stellbrink, L. Willner, O. Jucknischke, D. Richter, P. Lindner, L. J. Fetters, and J. S. Huang, Macromolecules, 31, 4189 (1998).

27. K. Suzuki, J. Oku, M. Takaki, H. Okabayashi, and C. J. O’Connor, Polym. J., 35, 938 (2003).

28. K. Suzuki, G. Katsumura, Y. Kondo, J. Oku, and M. Takaki, 


\section{K. SUZUKI et al.}

Kobunshi Ronbunshu, 49, 825 (1994).

29. K. Suzuki, J. Oku, H. Okabayashi, and C. J. O'Connor, Langmuir, 19, 7611 (2003).

30. R. K. Iler "The Chemistry of Silica-Solubility, Polymerization, Colloid and Surface Properties and Biochemistry," Wiley, New York, N.Y., 1979, p 175.

31. K. Izawa, T. Ogasawara, H. Masuda, H. Okabayashi,
M. Monkenbusch, and C. J. O'Connor, Colloid Polym. Sci., 280, 725 (2002).

32. H. Einaga, "Inorganic Synthesis in Solution as a Reaction Field,” Baifukan, Tokyo, 2000, p 169.

33. M. Takaki, K. Suzuki, Y. Kondo, and J. Oku, Polym. J., 23, 917 (1991). 